quality of the papers was concerned the congress was a success. The meetings were well attended and the papers followed with close attention, even in those few cases in which the authors were not able to attend in person.

The president, Sir Richard Temple, a contributor to the proceedings of the Society almost from its inception, in his address on "The Mystery of Mental Atmosphere," dealt with a topic of no little philosophic import. He sought the origin of magic in the attempt of the primitive mind to bridge the gap that philosopher and savage alike reach at the point which is beyond experience and passes understanding. Recalling an observation of his own on a voyage to Rangoon, which revealed to him that a personage, al-Khidr, had been identified among the people with almost every hero of the past and many smaller locai ones, he argued that such beings as this represent to the populace the unknown and mysterious by which they endeavour to bridge the gap, while the mind, clinging, as Andrew Lang suggested, to whatever it absorbs, modifies it, and by each contact produces an atmosphere which overlaps but never destroys those produced by previous contacts. Folklore, therefore, to be scientific in studying any given belief, should ascertain the mental atmosphere at the time of absorption of the people who had absorbed it.

The proceedings of the congress covered a wide range, both geographically and in subject matter. One of the most striking papers in its choice of subject was a study of stone-carrying women, by Mrs. Banks, who has followed up the persistent story in western Europe of women who dropped stones from creels on their shoulders or from their aprons, among whom even the Virgin Mary found a place. She sought to connect the legend with the clearing of land by women as early agriculturists.

Several contributors offered papers on extraEuropean folk-lore. Prof. Sayce, who was one of the original members of Council of the Society, dealt with Egyptian folk-lore, as did Miss Blackman in its medical aspect; Mrs. Spoer (Miss Goodrich-Freer) with Hebrew amulets; Capt. M. W. Hilton-Simpson with medical magic in Algeria. Prof. Starr sent a communication on Filipino magic, and Mr. R. E. Enthoven described beliefs connected with tree and animal worship in India, and showed the identity in the conception of tree, animal, and human soul.

Among papers dealing with the Near East were Prof. R. M. Dawkins on the study of folk-lore in modern Greece, and an interesting account of mummers' plays in Attica by Prof. H. J. Rose. Mrs. Hasluck deseribed " the most primitive people in Europe outside Russia"-the Sarakachan people, who spend the summer in the Pindus mountains and the winter in the plains of Macedonia. She has visited two branches of these people, one the Albanian Vlacks, and the Sarakachan peoples proper, who, curiously enough, owing to local conditions. have reverted from a settled to a nomadic life. Dr. Beza gave the congress a view of Rumanian folk-lore in his account of the work of Demetrius Contemir's contribution to folk-lore, and Prof. Gudmund Schütte dealt ably with the evidence for the worship of the bull among the Kimbri. In the evening session at the Imperial Institute, Prof. Pospisil, of Brno, gave an account illustrated by a kinematograph film of the folk dances and customs of Central Europe.

British folk-lore was well represented, and offered one of the most interesting of the papers presented at the congress in an account of witchcraft in Wales, of which perhaps the most striking feature was the extent to which the belief is still prevalent among the educated. A witch has been considered a more efficacious thief-finder than a policeman, and a piece of moleskin worn on the chest of more avail than a doctor. The use of written charms in English suggests an English origin for some forms of the belief. Mr. T. W. Thompson's interesting account of British gypsy marriage and divorce customs included references to the eating of the blood-cake and the jumping of the bride and bridegroom over a branch of flowering broom or a besom made of broom. A paper was presented on behalf of Canon MacCulloch discussing aspects of the Arthurian legend, and Miss Mona Douglas gave an account of various beliefs relating to animals in Manx folk-lore, according to which cows were held most susceptible to witchcraft, and the witch was believed to take the form of a hare. Miss B. C. Spooner described 'charming' in Cornwall, the counterpart of the modern faith-healing. A suggestive paper by Prof. Pettazzoni on confession among primitive people, described the confessional as an analogue of the expulsion of sin or disease by washing or drawing of blood, the evil being expelled by verbal enunciation.

A fitting climax to the prominence of witchcraft in the proceedings of the congress was a communication from M. P. Saintyves, which was read by M. Goblet, on the 'witches' sabbath,' in which the author maintained the existence of a magic religion and secret church of wizards in the Middle Ages.

The programme on the concluding day included papers on the psycho-analytic side of folk-lore. Dr. Ernest Jones, in dealing with the question generally, made special reference to the significance of beliefs relating to the number three. Dr. Roheim dealt with "Mother Earth and the Children of the Sun."

The social side of the congress was not neglected. It opened with a presentation of the delegates to the president by Prof. J. L. Myres, and the members were entertained by Dr. Henry Wellcome at the Historical Medical Museum, and by Mr. and Miss Canziani. Visits were paid to Oxford and Cambridge; the English Folk Dance Society gave a demonstration of folk-dances, folk-songs, and children's singing games.; and an official dinner was held on the concluding day.

\title{
Energy and Atoms.
}

A MESSEL memorial address, entitled "Available A Energy," was delivered by Prof. R. A. Millikan on Sept. 5 in New York at a joint meeting of representatives of the British Society of Chemical Industry and the Institution of Chemical Engineers with the American Institute of Chemical Engineers. As might be expected from Prof. Millikan's recent researches, his treatment of his subject proceeded upon somewhat unorthodox lines, and in the greater part of his lecture he was concerned with astronomical problems, rather than with the physical and engineering thermo. dynamics suggested by his title. The apology he made for offering an apparently abstract subject of this nature to a technical audience was the fact, perhaps usually insufficiently appreciated, that many of the distinctive features of modern civilisation come from our present knowledge of mechanics, which, in turn, was largely developed through the pioneer work done in the seventeenth and eighteenth centuries upon extra-terrestrial problems.

The fundamental work of Prof. Millikan and Dr. Cameron themselves upon the cosmic rays is by now

No. 3075, VoL. 122] 
well known, and it is unnecessary to elaborate here upon the way in which they have applied relativity and quantum theory to enable them to trace the origin of the penetrating radiation to a creation of certain light elements from protons and electrons, except again to emphasise, with Prof. Millikan, the importance in this connexion of Dr. Aston's work with the mass-spectrograph, and of Dr. Dirac's theoretical treatment of the absorption by matter of radiation of short wave-length.

In this address, however, Prof. Millikan has dealt with two other problems raised by his own work. The first of these is the question as to where atombuilding processes can proceed in the universe. His full arguments are not advanced-they are to be published in the October number of the Physical Review-but he states that there is excellent experimental proof that the nuclear combination which produces the cosmic rays does not take place in the stars at all, but at places of low pressure where the temperature is close to the absolute zero; in other words, in interstellar or intergalactic space. Combining this with the conclusions of Prof. Eddington and Sir James Jeans, he arrives at the picture of a continuous atom-destroying process taking place under the extreme conditions existing in the interiors of stars, and an atom-creating process taking place between the stars in the equally extreme conditions of an opposite kind obtaining there.

The second point raised, closely connected with the first, is the problem of why the primordial positive and negative electrons which go to build up the common elements have not been used up long ago. The answer which Prof. Millikan and Dr. Cameron make is " that out in the depths of space where we actually observe through the cosmic rays helium, oxygen, and silicon being continually formed out of positive and negative electrons, there too these positive and negative electrons are also being continually replenished through the conversion back into them under the conditions of zero temperatures and densities existing there, of the radiation continually pouring out into space from the stars." With the aid of this assumption, they can regard the universe as being already in a steady state, and can avoid the necessity for supposing that it must finally suffer a 'heatdeath,' in contradiction to the conceptions of Sir James Jeans, who supposes that the process of conversion of mass into radiant energy is nowhere reversible (NATURE, 121, 467; 1928), and of others who suppose that the processes are all everywhere reversible.

In his concluding remarks, Prof. Millikan discusses in a general way what sources of power are likely to be used in the future, although he suggests little that is new. Any extensive application of the energy available through the disintegration of radio-active or other atoms is dismissed, as is use of the almost unlimited energy which would be obtained if the hydrogen atoms of terrestrial water could be induced to build themselves up into atoms of other elements, since it is impossible to imitate the conditions of interstellar space under controllable conditions, and he comes ultimately to the conclusion that solar energy, in some form or another, must continue to supply most human needs.

\section{University and Educational Intelligence.}

CAMBRIDGE. - The retiring Vice-Chancellor, the Rev. G. A. Weekes, announced on Oct. 1, that the University has received an offer from the International Education Board of the Rockefeller Foundation of a gift of $£ 700,000$, of which $£ 250,000$ would be for the proposed new library and the remainder "for certain new developments in the physical and biological studies of the University." The gift is conditional on the University raising the money required to complete the whole scheme. As regards the University Library, it will be remembered that provisional plans for a new building costing $£ 500,000$ for construction and maintenance have been under consideration, and the Finance Board decided that $£ 250,000$ could be raised to enable a portion of the work to be started. The Rockefeller gift of $£ 250,000$ would make it possible to proceed with the whole building at once. The remaining $\$ 450,000$ is offered towards necessary developments of physical and biological studies, the complete scheme of which will cost $£ 679,000$; the University has thus to raise a further sum of $£ 229,000$ in order to be able to accept the Rockefeller gift.

LONDON.-The following courses of free public lectures at University College are announced "Recent Work on Vitamins," by Prof. J. C. Drummond, on Oct. $12,19,26$, Nov. 2,9 , and 16 ; "Urinary Secretion," by Prof. E. B. Verney, on Oct. 15, 22, 29 Nov. 5, 12, and 19. The lecture hour will be 5 o'clock and no tickets will be required.

DURING the forthcoming Michaelmas term courses of lectures will be given at the British Institute of Philosophical Studies by Prof. L. J. Russell on "Four Great Philosophers and the Modern Outlook," and by the Director of Studies, Mr. Sydney E. Hooper, on "Contemporary Philosophy." Full syllabuses can be obtained from the temporary offices of the Institute, 88 Kingsway, London, W.C.2.

From the University of Colorado we have received its Annual Catalogue with announcements for 1928-29, -a volume of some $\mathbf{5 0 0}$ pages, wherein are to be found interesting illustrations of several modern American departures from the traditional idea of a university. The Summer Quarter has assumed a very prominent place among the university's activities and is an important factor in the maintenance and improvement of the standards of teaching in the schools throughout the State. The students enrolled, largely school teachers, principals, and superintendents of education, numbered in last year's summer quarter 3363, as compared with a total attendance of students during the regular academic terms of 3131 . The University plant is thus kept working at full pressure almost throughout the year. The University's Extension Division, organised "to render to the State at large such public service as may lie within its power," comprises a Department of Instruction, including correspondence, class, and visual instruction, and homereading courses, and a Department of Public Service. Among the services of this department are : industrial surveys directed towards the ascertainment of opportunities for future expansion and growth of the industries of a selected district, retail cost surveys undertaken in co-operation with retail trade associations, public utility researches, a clearing house of information for municipal officials, assistance to civic organisations by scientific investigation of stated problems and drafting bills, organising conferences and exhibitions in connexion with public health, child welfare, community recreation and juvenile delinquency, a clearing house for the newspapers of the State, maintaining contact between the editors and the organised industries, and organisation of debates in high schools. The development of correspondence study is noteworthy, the enrolment in these courses having increased steadily from 150 to 1500 in the past ten years.

No. 3075 , VoL. 122] 